The 30th Symposium on Powder tchnology, was held on September 5, 1996 in the Tokyo Sanseido Cultural Hall, sponsored by the Hosokawa Powder Technology Foundation and supported by the Hosokawa Micron Corporation.

This symposium centered around functional composite materials for coping with the problems on resources, environment and energy and the adopted theme was "production and processes on the Latest Functional Compsite Materials."

Four lectures were given on the subject. The symposium was a great success with serious participants filling the 150 seat capacity hall.

\title{
The 30th Symposium on Powder Technology
}

Theme: The Production and Processes of the Latest Functional Materials

\section{Session 1 Characteristics and Applications of Materials Related Clean Energy Chairmanship T. Senna (Keio Univeristy)}

- Application of Solid Electrolytes to Resources, Environment and Energy

- Nickel-Hydrogen batteries
Taakashi Hibino

(National Industrial Research Institute of Nagoya)

Osamu Yamamoto

(Central Research Center, Matsushita Electric Industrial Co., Ltd.)

\section{Session 2 Production of Functional Materials and Related Problems \\ Chairmanship H. Tsuji (Osaka University)}

- Production Proceses and Performance of Functional Composite using Powder Materials

- Application of Powder Technology to Production of Functional Materials
KONA Awardee, Kei Miyanami

(University of Osaka Prefecture)

Toyokazu Yokoyama

(Hosokawa Micron Corporation)

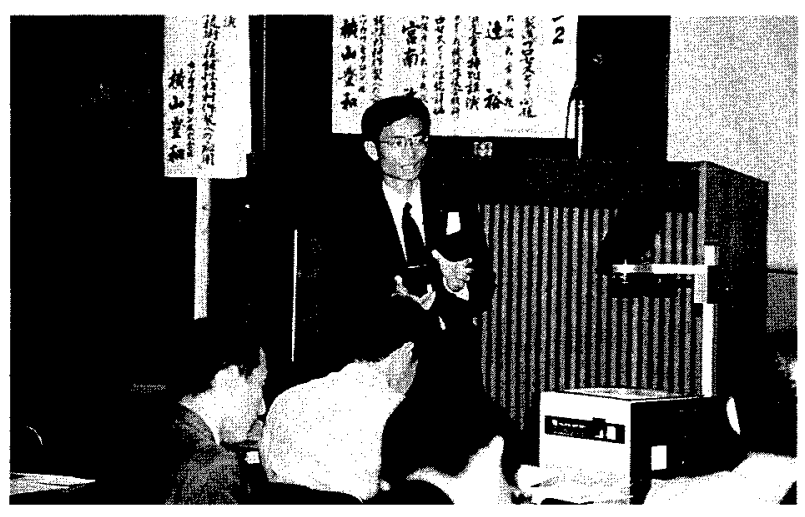

